\title{
The Application and Research of Intelligent All-in-One Card in the Smart Campus of Colleges and Universities
}

\author{
Xiaoling Zhou \\ Center of Information Development and Management, Changzhou University, Changzhou, China \\ Email: kitty@cczu.edu.cn
}

How to cite this paper: Zhou, X.L. (2018) The Application and Research of Intelligent All-in-One Card in the Smart Campus of Colleges and Universities. Journal of Computer and Communications, 6, 82-91. https://doi.org/10.4236/jcc.2018.68006

Received: July 9, 2018

Accepted: August 27, 2018

Published: August 30, 2018

Copyright $\odot 2018$ by author and Scientific Research Publishing Inc. This work is licensed under the Creative Commons Attribution International License (CC BY 4.0).

http://creativecommons.org/licenses/by/4.0/

\begin{abstract}
With the in-depth application of smart campus in its first period, universities and teachers have a more urgent need to deepen the application of all-in-one card in smart campus. This paper introduces the platform upgrade technology of all-in-one card application system, near field communication (NFC) card technology and application of mobile payment technology in smart all-in-one card, and makes solid progress in the post-renovation and construction of intelligent all-in-one cards in smart campus of colleges and universities, in order to provide sustainable guarantee and guidance for the development of colleges and universities.
\end{abstract}

\section{Keywords}

Campus Card 3.0 System, NFC All-in-One Card, Mobile App

\section{Introduction}

The campus all-in-one card system of colleges and universities was generally established early this century. As an effective information carrier for college or university students, campus cards have involved the fields of teaching, research, management and life services. With the deep application of smart campus in colleges and universities, teachers and students have an increasingly prominent demand for humanized, intelligent and diversified campus all-in-one card system. Along with the construction of new campus, it is necessary to speed up the upgrading and construction of the all-in-one card system in order to turn the all-in-one card into intelligent all-in-one card, which as a result was integrated into the platform of smart campus and became an indispensable component and functional support of smart campus [1] [2] [3] [4]. 
This article mainly introduces the construction target, the construction content, the practical application of the smart card system in the university campus, and further realizes the important role of the one card system in the intelligent campus.

\section{Construction Goals}

\subsection{Complete the Background Upgrade of All-in-One Card System}

The functions of existing platform are relatively backward. Supporting hardware products have the serious aging problem due to its long-time usage. The spare parts market is becoming less and less, which cannot support the mainstream CPU cards in the market. In the construction of the new campus, designs with high starting point will adopt CPU card matching consumer equipment and identity management equipment. Therefore, it is necessary to upgrade the background of the all-in-one card system to the mainstream 3.0 service platform, in order to realize the transition from M1 card to CPU card, connect the multi-campus all-in-one card system, and provide stable, safe and efficient guarantee.

\subsection{Enrich the Application of Smart Campus All-in-One Cards}

Focusing on the needs of teachers and students to use mobile devices such as smart phones, functional upgrades such as NFC mobile phone card payment, mobile all-in-one card App, intelligent access control, self-service card will be realized. It will promote the diversification and use of fast payment, and the smart learning and life experience of teachers and students on campus.

\section{Construction Content}

1) System platform upgrade

The system platform will be upgraded from 2.6 version to 3.0 version to fully support M1 card, CPU card and other card types. It will have functions of no card payment, service, and improving management platforms, as shown in Figure 1.

- A system platform integrating functions of campus M1 card and CPU card payment for financial services.

- Payment and transfer platform integrating electronic currency and online payment services.

- Open platform compatible with all kinds of third-party application systems.

- An audit service security platform with advanced technologies, such as log audit, database audit and dynamic password verification introduced.

- A comprehensive information platform for operation and maintenance services is built by using data monitoring, equipment monitoring, operation and maintenance services, SMS service system and Internet of things technology.

- Open all kinds of business flow generated by all-in-one card, explore and utilize data values deeply to provide a reliable data platform for school decision support. 


\section{Campus card 3.0}

Basic system

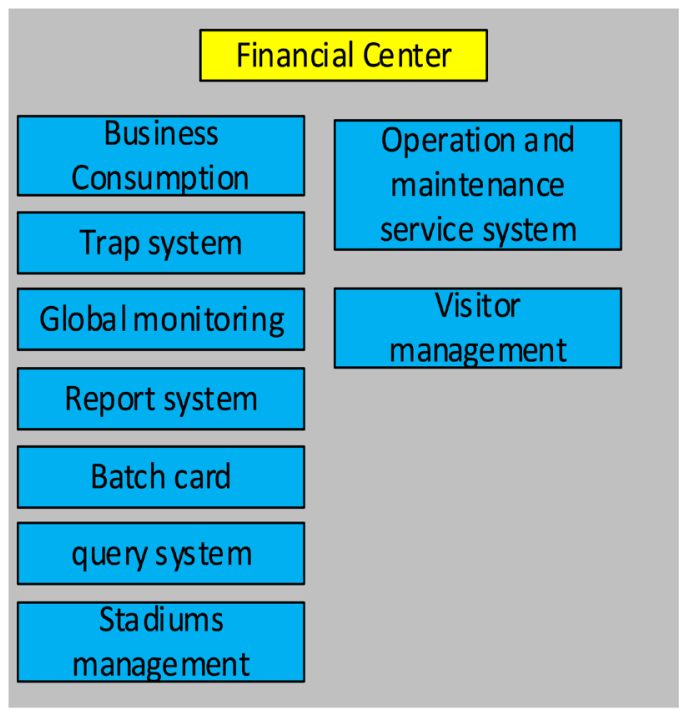

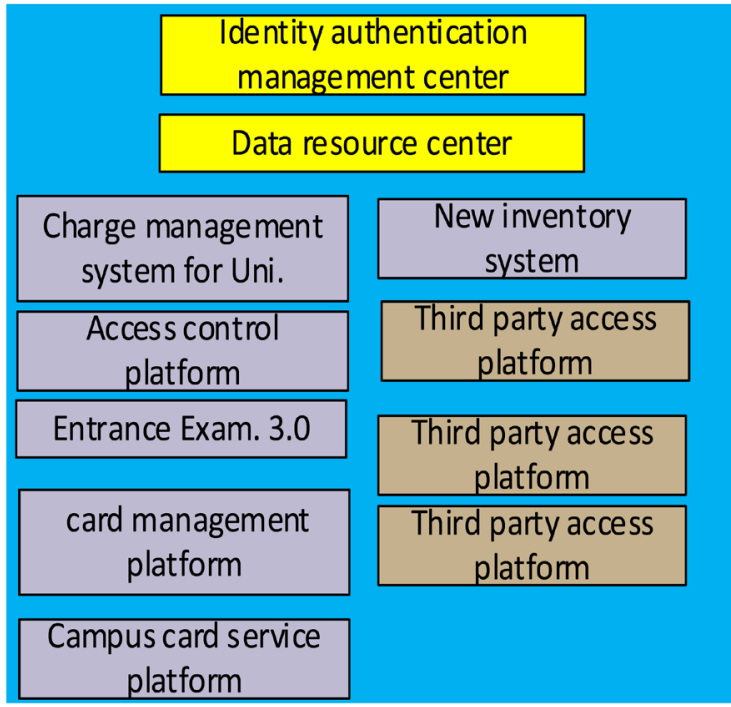

Figure 1. Campus card 3.0.

- Service platform which improves the short board of the existing all-one card system in the operation process, optimizes the business process, and standardize the management.

2) The financial center mainly aims at trading services and management in the process of using cards to replace currency. It is the core and basic service of the all-in-one card system. It includes financial services such as account management, accounting settlement, recharge transfer, collection and payment and is responsible for the storage and backup of financial data and the provision of data source services to the data resource service center. The new platform makes full use of the link between the card and the bank to build a unified payment platform, which provides a unified, safe and convenient channel for system payment (Such as applications of paying network fee, registration fee, make-up examination fee, online meal order, venue reservation, telephone fee payment, water and electricity payments).

3) The identity authentication management center provides uniform single sign-on based on identity authentication, and data support for realizing smart campus, constructing unified login and permission management. For the reformable applications, the authentication interface of the unified authentication platform is invoked. It supports JSP, ASP, PHP, ASP.NET, VB and other languages. Open the system LDAP interface for applications with large concurrency to realize fast reading and authentication of identity data. As to life cycle management of identity data, lifecycle instrumented management of identity data, visualized identity changes and transformation monitoring are provided, batch import and export are supported to make it easy to manage. It also provides ab- 
normal change notification and informs system administrator timely.

4) The bank transfer system is the key link between the campus card and bank card. At present, there is mainly transaction machine system. As emerging payment tools, Alipay and WeChat are loved by teachers and students in colleges and universities, because they have more functions, and are convenient and fast to use. Our company has cooperated with Alipay company to store Alipay in campus cards. In order to make it more convenient for teachers and students to recharge their campus cards, this project plans to cooperate with Tencent WeChat and realize the implementation of WeChat payment into campus card, in order to realize convenient functions such as self-service for re-making cards, and online payment and recharge.

5) Batch card issuing system provides one-stop solution for photo collection, campus card printing, matching, issuing and card supplementing, on the basis of original discrete card printer, document photo acquisition equipment. It is not necessary to initiate a photo card manually, which can greatly reduce the amount of work and error of issuing cards in batch at new students' enrollment. It can reduce the slowness caused by peak centralized access to network initialization servers, improve the speed and efficiency of card issuance, and also improve the quality of image acquisition and card printing. The business process is shown in Figure 2.

6) Report assist decision-making system provides information service for school management by the statistical analysis on the all-in-one card data of

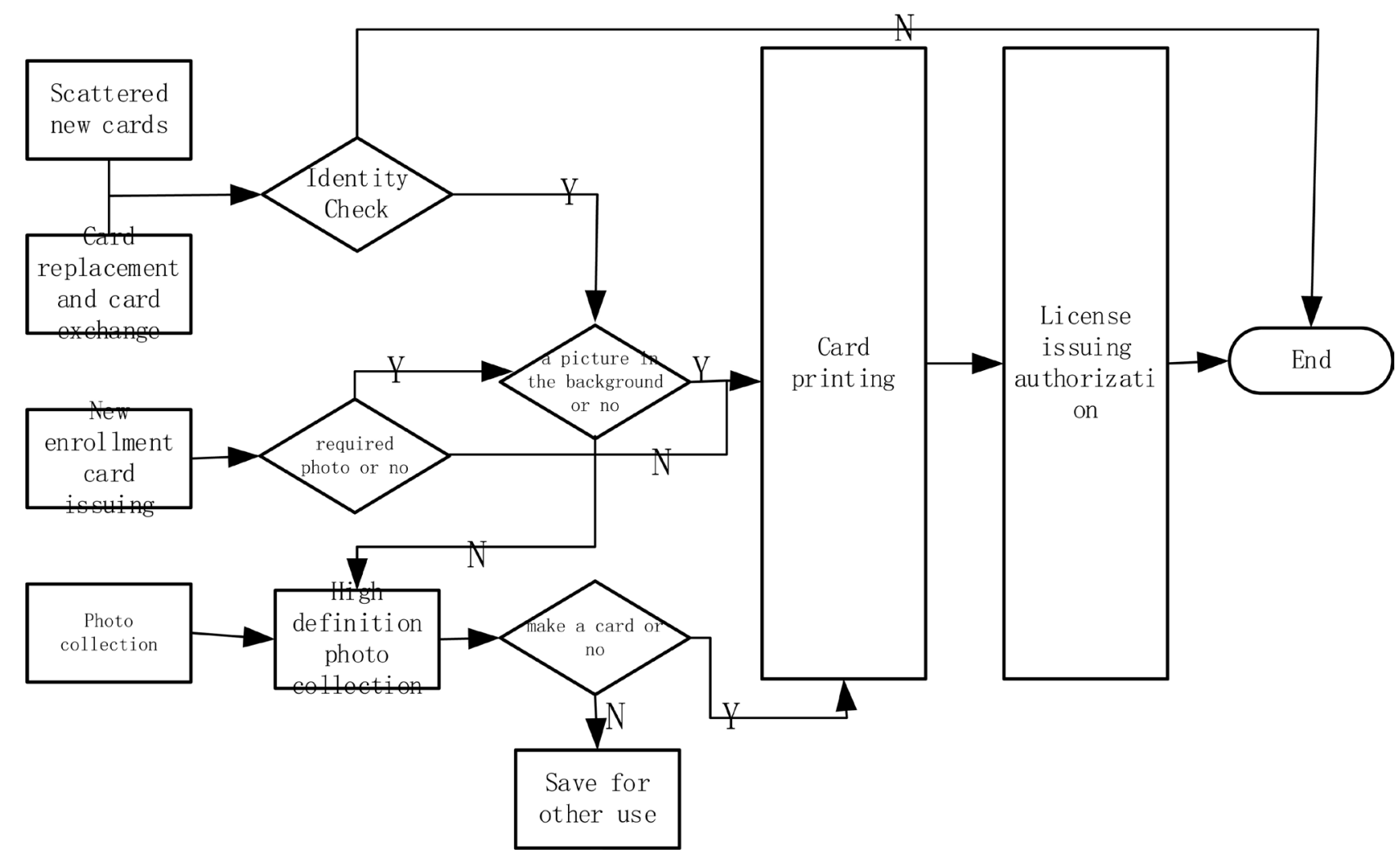

Figure 2. Batch card system. 
learning, work and consumption of teachers and students, and by graphical display analysis results. Main functions include data statistics, consumption statistics, operation statistics and management statistics.

\section{The Application of Intelligent All-in-One Card}

\subsection{The Application of NFC All-in-One Campus Card}

NFC has the characteristics of low cost, easy to use and more intuitive, which make it more potential in the field of all-in-one card [5]. NFC can achieve the communication of various equipment within a few centimeters, through a combination of a chip, an antenna and some software. It has greatly changed the way people use many electronic devices, even change the way they use credit cards, keys and cash.

With the development of mobile payment technology, mobile phone campus card has become an important supplement to campus card [6]. Mobile phone campus card support dual mode frequency, primary and secondary card mode. It realizes the coexistence of mobile phone card and campus card. Besides the main functions of traditional campus card, it has other functions such as SMS platform, mobile transfer payment and mobile payment. It can interactively query about information of scheduled classes, meetings, book borrowing, consumption, account balance through SMS, WAP and other ways. It can specify and send all kinds of information with the function of notification and reminder. And it can achieve online payment through text message, UTK menu and other ways. When eating, printing and supermarket shopping, students and teachers don't have to use meal cards and pay cash.

With the popularity of NFC smartphones, POS terminal renovation, the three operating companies' pushing, unification of domestic standards, the NFC industry applications are increasingly diversified. The colleges and universities students with post-90s generation as majority pay more attention to new and simple user experience, so the NFC campus card will be the inevitable trend of the development of the all-in-one card.

The project relies on the existing all-in-one card system. The upgraded and transformed part is shown in Table 1 .

\subsection{Mobile All-in-One Card App}

"Mobile all-in-one card" mobile phone client provides campus cardholders with the application of the all-in-one card system on the mobile phone, which is the product of deep integration of "campus all-in-one card" and mobile platform. It makes full use of network resources, let user operation more convenient, and realizes the smoothly transplantation of the high frequency application of campus informatization from PC to mobile phone [7] [8].

"Mobile all-in-one card" can connect with the unified identity authentication of the school, and control its scope and function according to permission. Campus card platform can be used to push all kinds of personal information to 
Table 1. System upgrade and transformation content table.

\begin{tabular}{|c|c|c|c|}
\hline Name & Upgraded content & Provided interface & Remarks \\
\hline \multirow{3}{*}{$\begin{array}{l}\text { Campus } \\
\text { card } \\
\text { platform }\end{array}$} & $\begin{array}{l}\text { All-in-one card background } \\
\text { upgrade }\end{array}$ & Provide interface protocol for online payment & \\
\hline & $\begin{array}{l}\text { Software system of all-in-one card } \\
\text { platform }\end{array}$ & $\begin{array}{l}\text { Provide special trading and inquiry interfaces for account opening and online } \\
\text { payment }\end{array}$ & \\
\hline & All-in-one card of mobile App & & \\
\hline \multirow[t]{7}{*}{$\begin{array}{l}\text { Hardware } \\
\text { equipment }\end{array}$} & Consumption machine & $\begin{array}{l}\text { 1) Consumer machines hardware upgrades to support NFC card reading and } \\
\text { writing }\end{array}$ & \\
\hline & & 2) Consumer machines monitoring upgrades & \\
\hline & Attendance machine & 1) Attendance machine hardware upgrades to support NFC card reading & \\
\hline & & 2) Attendance machine monitoring upgrades & \\
\hline & Access control device & 1) Access control card reading hardware upgrades to support NFC card reading & \\
\hline & & 2) Access control device monitoring upgrades & \\
\hline & Other devices & $\begin{array}{l}\text { Hardware and monitoring of the transaction machine upgrades; Electrical control } \\
\text { hardware and monitoring upgrades; Channel machine, identity authentication and } \\
\text { other card reading equipment and monitoring upgrades; Water controls don't } \\
\text { allow phones to swipe a card }\end{array}$ & \\
\hline Card & NFC test card & $\begin{array}{l}\text { The NFC test card dealers is designated by the operating companies and provides } \\
\text { related read and write card instructions and test cards }\end{array}$ & \\
\hline \multirow[t]{3}{*}{$\begin{array}{l}\text { Operating } \\
\text { companies }\end{array}$} & China Mobile & $\begin{array}{l}\text { 1) Provide access specifications and on-site test upgrade personnel } \\
\text { 2) Provide TSM platform access specifications and on-site test upgrade personnel }\end{array}$ & \\
\hline & China Telecom & $\begin{array}{l}\text { Provide interface access to China Telecom TSM platform, specifications and } \\
\text { on-site test upgrade personnel }\end{array}$ & \\
\hline & China Unicom & $\begin{array}{l}\text { Provide interface access to China Unicom TSM platform, specifications and on-site } \\
\text { test upgrade personnel }\end{array}$ & \\
\hline
\end{tabular}

mobile phone platform. It provides all kinds of users with fast, unimpeded and readily accessible information services. The cardholder only needs to use the smart phone to complete the functions of identity authentication, payment of fees, inquiry of all-in-one card related information, binding the bank card for payment transfer, reporting the loss of the card and receiving notifications. It achieves the interaction between smart card and mobile phones, transforms the traditional and complex campus card into personalized and situational applications on mobile phones. Main functions are shown in Figure 3.

When the balance is insufficient, teachers and students can be recharged at any time directly through the online payment function, as shown in Figure 4.

1) The mobile client issues an online payment application to the card. 2) The card generates MAC1 to the client. 3) The client initiates a recharge authentication request to the online payment platform. 4) The online payment platform sends the recharge authentication information to the application provider. 5) Then the application provider gives the authentication reply to the online payment platform. 6) Online payment platform generates authentication orders, initiate orders. 7) The payment provider returns to the frequently referenced 


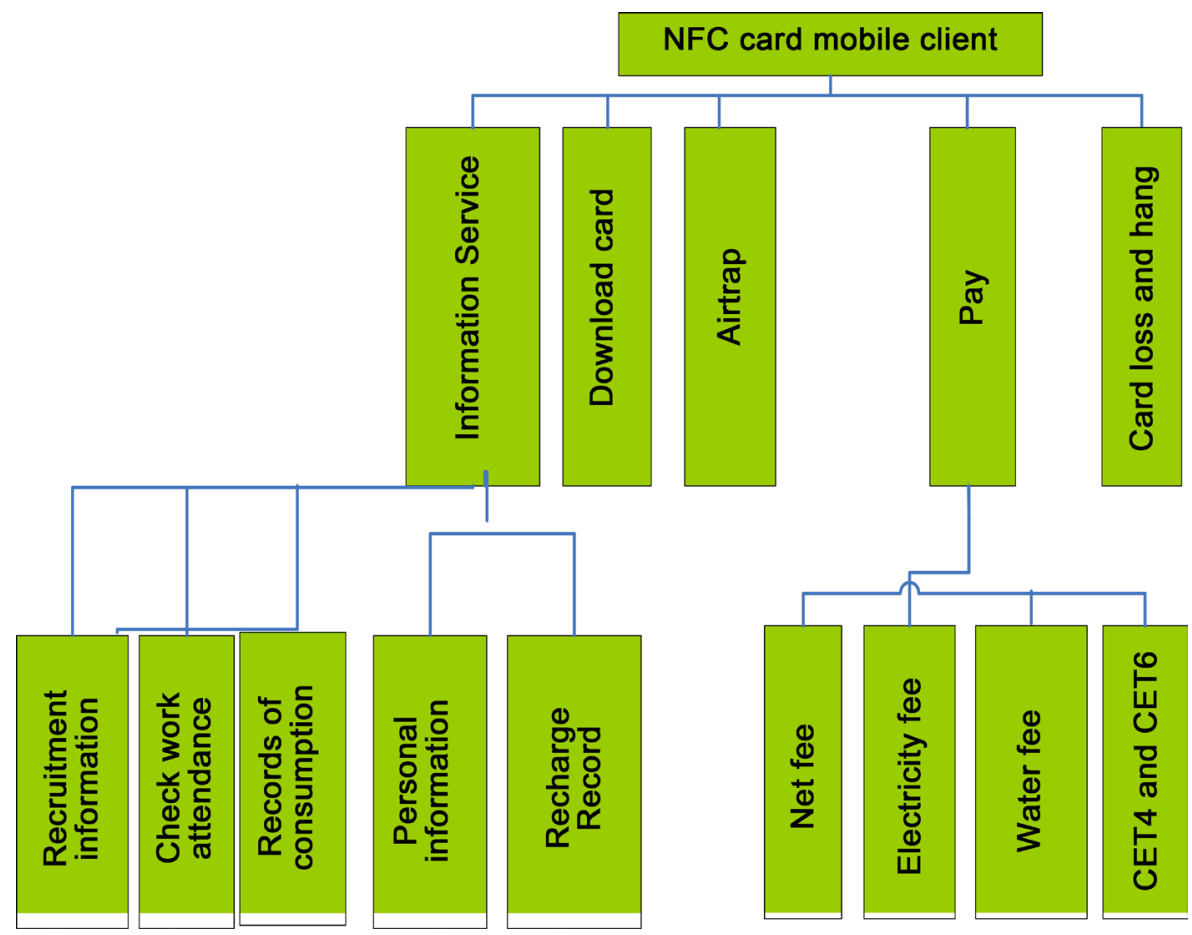

Figure 3. Card application.

Payment provider
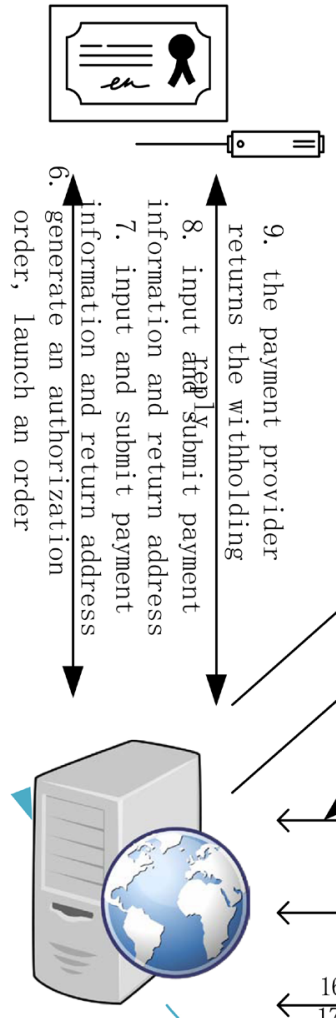

Air trap platform
Mobile client

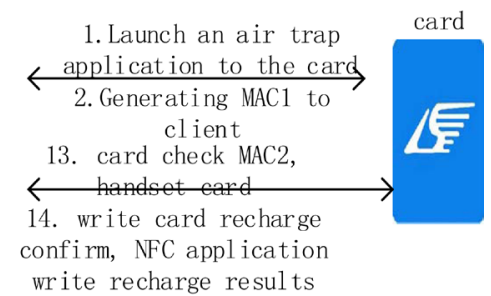

Figure 4. Air trap. 
payment page. 8) Enter and submit payment information and return to the address. 9) The payment provider returns to a reply to the deduction. 10) The online payment platform records the order status, and applies for write card. 11) The application verifies the MAC1, returns to the write card instruction, and generates MAC2. 12) The online payment platform notifies the mobile clients of the instruction to write card. 13) The card verifies MAC2, and mobile phones write cards. 14) Confirm write card recharge, write NFC application into recharge results. 15) Notify the success of write card, and return to the recharge result tag. 16) Push the information of write card success to the application provider system, and return to tag. 17) Application provider system checks the tag, changes the status of the recharge transaction and the recharge ends.

NFC mobile phones can download a card online, fill in personal information on the phone client, and then the card can be sent out from the phone, as shown in Figure 5.

Once the mobile phone is lost, student can report the loss through other students' "NFC mobile phone".

In dormitory, classroom, library and other places, students take their cell phone and swipe them on the access control card reader, and then they will pass through authentication and be able to enter their dorm room.

Through self-service card replacement system, it can effectively solve the outstanding problem that students cannot live and consume when students lose card on non-weekday, and it relieves the hard work of staff from multi-campus frequent rush.

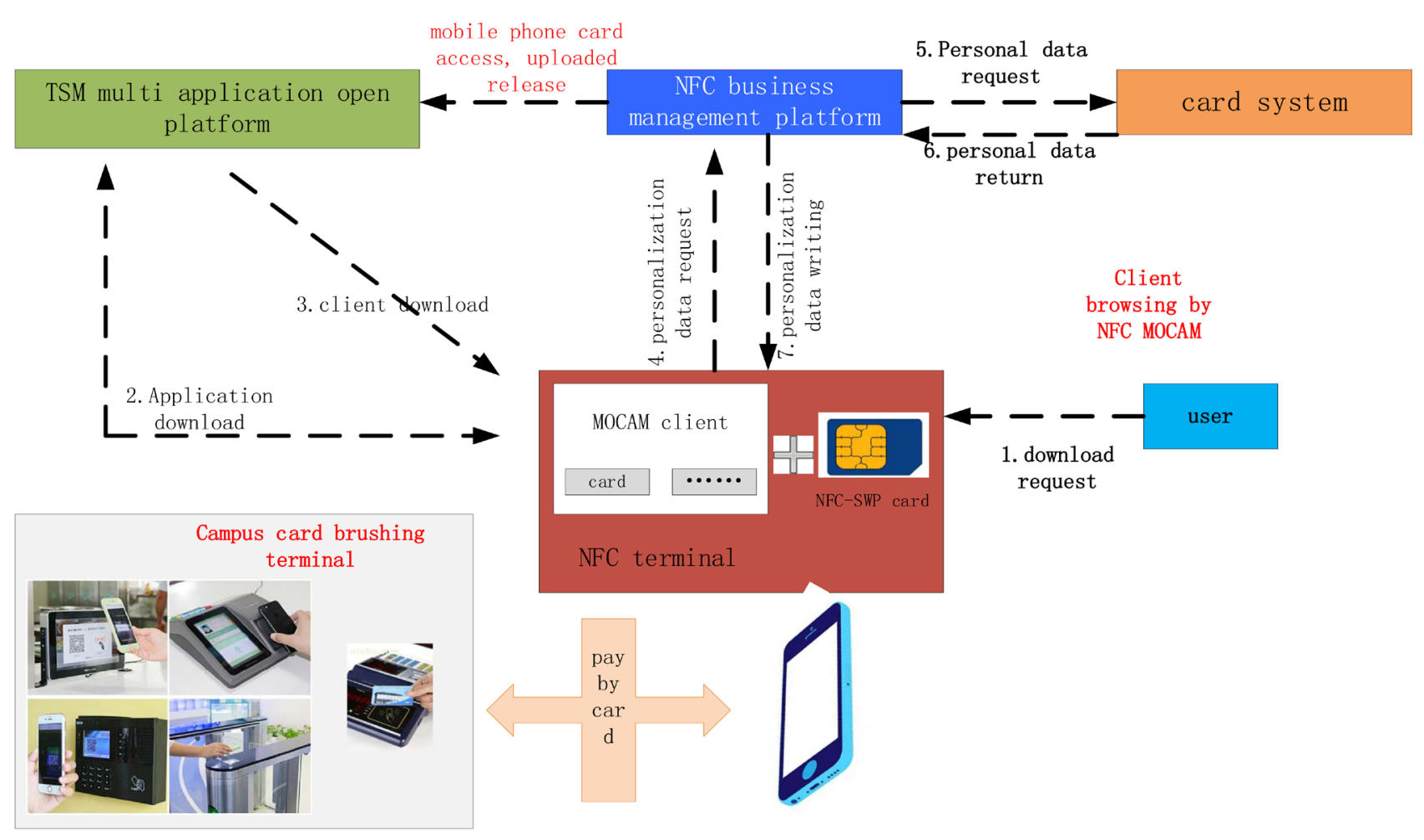

Figure 5. Download the card. 
The all-in-one card has other functions. It can check balances and usage records at any time and anywhere, it has access to campus notices, course and examination arrangements, examination results, recruitment information and so on.

\section{Conclusion and Prospect}

Intelligent all-in-one card is an indispensable link in the construction of smart campus. It faces the following three trends in its future construction and development: 1) Remove the card. That means the change from traditional hard cards to mobile terminals or rings. Mobile terminals are represented as scanning payment, NFC, etc. 2) The consumption account funds will change from internal accounts to mainstream payment account funds such as bank cards, Alipay and WeChat. It needs to make full use of its strengths and avoid its weaknesses, actively incorporate multiple payment source, and provide customized services. As an important support for the construction of smart campus, the intelligent all-in-one card will certainly be improved with the continuous development of the smart campus. It will also become an important guarantee to support school teaching, scientific research and other core work and promote the rapid improvement of school quality. It can provide advanced and intelligent application service platform for school management, strong support for school decision-making, intelligent working and living environment for teachers and students. It enhances the work and innovation motivation of teachers and students, and explores a successful practical path for the local colleges and universities information construction at the same time, which as a result strengthens the demonstration effect and school influence [9] [10].

\section{Funding}

This paper is the stage achievements of the application and research of "smart card" in smart campus of colleges and universities, a key topic of 2017 Jiangsu province modern education technology research (project number: 2017-R-59455).

\section{Conflicts of Interest}

The authors declare no conflicts of interest regarding the publication of this paper.

\section{References}

[1] Guo, X. and Dai, Y. (2017) A Case Study of Campus All-in-One Card Upgrading and Renovation Project-Dalian Medical University Campus Card System Upgrade and Transformation Project. The Chinese Journal of ICT in Education, 9, 73-76.

[2] Chen, Y.X., Zhang, J.G. and Meng, Y.J. (2017) Selection and Design of Contactless CPU Card Based on Intelligent All-in-One Card. Journal of Central China Normal University (Natural Science Edition), 51, 38-42.

[3] Tian. L. (2015) Construction of Campus All-in-One Card in Smart Campus Environment. Journal of East China Normal University (Natural Science Edition), 
530-535.

[4] Sun, F.T. (2018) The Application of All-in-One Card in Campus Informatization. China New Communications, 144-145.

[5] Wu, J.C., Xie, Z.H., Yu, H.L. and Wu, G.Y. (2017) Mobile E-Commerce System of Guangdong Traffic Card Based on NFC Terminal. China Traffic Information, 140-142.

[6] Wu, H. and Liu, D.X. (2018) Digital Campus Card System Design. Wireless Interconnect Technology, 58-60.

[7] Sui, G.F. (2018) Discussion on Smart Campus Smart Card Technology and Safety Design. Electronic Production, 74-75.

[8] Zhang, Q.L. (2017) Modeling of Campus Smart Card System in Digital Campus. Hubei University of Technology, Wuhan.

[9] Cao, M.X. (2016) Design and Implementation of Campus Smart Card System. Beijing University of Technology, Beijing.

[10] Huang, C.N. and Sun, J. (2016) Construction of All-in-One Card System and Service System in Smart Campus Environment. Computer Knowledge and Technology, 4-5. 